\title{
Gnidia glauca Leaf and Stem Extract Mediated Synthesis of Gold Nanocatalysts with Free Radical Scavenging Potential
}

Sougata Ghosh ${ }^{1,2}$, Sumersing Patil', Niraja B. Chopade', Soching Luikham², Rohini Kitture ${ }^{3}$, Deepanjali D. Gurav ${ }^{4}$, Ajay B. Patil ${ }^{4}$, Suvarna D. Phadatare $^{4}$, Vyankat Sontakke ${ }^{4}$, Sangeeta Kale ${ }^{3}$, Vaishali Shinde ${ }^{4}$, Jayesh Bellare ${ }^{5}$ and Balu A. Chopade ${ }^{1,6 *}$

${ }^{1}$ Institute of Bioinformatics and Biotechnology, University of Pune, Pune, India

${ }^{2}$ Modern College of Arts, Science and Commerce, Ganeshkhind, Pune, India

${ }^{3}$ Department of Applied Physics, Defense Institute of Advanced Technology, Girinagar, Pune, India

${ }^{4}$ Garware Research Centre, Department of Chemistry, University of Pune, Pune, India

${ }^{5}$ Department of Chemical Engineering, Indian Institute of Technology, Bombay, Powai, Mumbai, India

${ }^{6}$ Department of Microbiology, University of Pune, Pune, India

\begin{abstract}
Development of eco-friendly and novel method for the synthesis of metal nanoparticles is one of the most popular and emerging aspect of nanobiotechnology. In this report, Gnidia glauca leaf and stem extract are used to synthesize gold nanoparticles (AuNPs). As compared to other biological methods, the syntheses were extremely rapid leading to complete reduction within $20 \mathrm{~min}$. Transmission and high resolution transmission electron micrographs clearly indicated that majority of the bioreduced nanoparticles were spherical within a size range of 10 to $60 \mathrm{~nm}$. Exotic shapes like gold nanotriangles and nanohexagons were found in a range between 100 to $300 \mathrm{~nm}$. Dynamic light scattering validated the size range that was observed in TEM and HRTEM. Unique pattern confirming the self-assembly of spheres into anisotropic nanoparticles of larger dimensions was exhibited in HRTEM images. X-ray diffraction pattern and energy dispersive spectroscopic analysis confirmed the purity of elemental gold in the bioreduced nanoparticles. Fourier infrared spectral analysis indicated the role of the phenolic groups in reduction of chloroauric acid into AuNPs. Efficient reduction of 4-nitrophenol (4-NP) to 4-aminophenol (4-AP) in the presence of AuNPs and $\mathrm{NaBH}_{4}$ with apparent rate constants (k) $1.99 \times 10^{-3} \mathrm{~min}^{-1}$ and $4.498 \times 10^{-3} \mathrm{~min}^{-1}$, for AuNPs reduced by GGLE and GGSE, respectively provided strong evidence for the catalytic potential. AuNPs synthesized by GGSE and GGLE showed a second order rate constant of $1.78 \times 10^{7}$ and $1.31 \times 10^{7}$ respectively confirming the scavenging of $A B T S \cdot+$ radicals.
\end{abstract}

Keywords: Gnidia glauca leaf and stem; Gold nanoparticles; HRTEM; Pulse radiolysis; Nanocatalyst

\section{Introduction}

Synthesis of nanoparticles with a controlled shape and size is one of the most promising research areas in material science $[1,2]$. Attractive crystallographic and morphological characteristics direct the optoelectronics and biological properties $[3,4]$. Thus nanoparticles with anisotropic properties, particularly gold nanoparticles (AuNPs) have found immense applications in electronics, sensing and medical biotechnology [5,6]. Various chemical methods like wet chemical synthesis, solutions phase methods, reverse micellar or polyol process and template-based methods using nanoporous silica, polycarbonate membranes or carbon nanotubes as well as physical methods like photochemical, microwave assisted, radiolysis and sonochemistry mediated synthesis of metal and metal oxide nanoparticles are available [7-12]. However, the aforementioned methods for synthesis of AuNPs involve hazardous agents that are considered as potent environmental pollutants and carcinogens.

Therefore, presently the increasing interest towards the biological methods has helped in developing new clean, cost-effective and efficient synthesis techniques. Recently, bacteria, yeast, fungi and plant extracts have been investigated for their ability to synthesize AuNPs [13-21]. It is important to note that medicinal plants are preferred due to their biocompatibility and rapid synthesis [14,21]. Recently we have reported the synthesis of gold nanoparticles using tuber extract of $D$. bulbifera, a potent medicinal plant [22]. Similarly, recently synthesis of AuNPs have been reported employing leaf extract of medicinal plants such as, Azadirachta indica, Cinnamomum camphora, Cinnamomum zeylanicum, Eucalyptus camaldulensis and Murraya koenigii [23-27]. However, there are no reports on the potential of leaf and stem extracts of Gnidia glauca for synthesis of AuNPs.
G. glauca is known to have immense medicinal values in treatment of sore throat, abdominal pain, wounds, burns, snake bites. Leaves have been applied to treat the contusions, swellings, back ache and joint aches [28]. Similarly, recently we have reported its antidiabetic activity [29].

The low cost biogenic AuNPs are required to be evaluated for their potent industrial applications. Hereby many model reactions are established for rapid screening of industrially important metal nanoparticles. Thus in order to study the catalytic activity of AuNPs, the reduction of 4-nitrophenol (4-NP) to 4-aminophenol (4-AP) by sodium borohydride $\left(\mathrm{NaBH}_{4}\right)$ in aqueous phase is chosen as a model reaction. This reaction is widely used to evaluate the catalytic activity of AuNPs. The reaction does not proceed without catalyst [30-32].

In this work, we investigated the biosynthesis of AuNPs employing G. glauca leaf and stem extract (GGLE and GGSE, respectively). The synthesis was optimized and the bioreduced AuNPs were characterized employing UV-Visible spectroscopy, transmission electron microscopy, high resolution transmission electron microscopy, energy dispersive

*Corresponding author: Chopade BA, Babasaheb Ambedkar Marathwada University, Jaisingpura, Aurangabad, India, Tel: 912403334; E-mail: chopade@ unipune.ac.in

Received February 07, 2016; Accepted March 01, 2016; Published March 08 2016

Citation: Ghosh S, Patil S, Chopade NB, Luikham S, Kitture R, et al. (2016) Gnidia glauca Leaf and Stem Extract Mediated Synthesis of Gold Nanocatalysts with Free Radical Scavenging Potential. J Nanomed Nanotechnol 7: 358. doi:10.4172/21577439.1000358

Copyright: ( 2016 Ghosh S, et al. This is an open-access article distributed under the terms of the Creative Commons Attribution License, which permits unrestricted use, distribution, and reproduction in any medium, provided the original author and source are credited. 
Citation: Ghosh S, Patil S, Chopade NB, Luikham S, Kitture R, et al. (2016) Gnidia glauca Leaf and Stem Extract Mediated Synthesis of Gold Nanocatalysts with Free Radical Scavenging Potential. J Nanomed Nanotechnol 7: 358. doi:10.4172/2157-7439.1000358

spectroscopy, X-ray diffraction spectroscopy and fourier transform infrared spectroscopy. AuNPs were evaluated for its catalytic potential and scavenging activity against pulse radiolysis generated $\mathrm{ABTS}^{\cdot+}$ radicals.

\section{Materials and Methods}

\section{Preparation of plant extracts}

G. glauca leaf and stem were collected from Western Ghats of Maharshtra, India. The plant materials were chopped and shade dried for 2 days at room temperature followed by grinding into fine powder. G. glauca leaf extract (GGLE) and stem extract (GGSE) were prepared by suspending $5 \mathrm{~g}$ of powdered sample in $100 \mathrm{~mL}$ of distilled water followed by boiling for $5 \mathrm{~min}$. After decanting the extract was filtered through Whatman filter paper No.1 and the filtrate was stored at $4^{\circ} \mathrm{C}$.

\section{Synthesis of gold nanoparticles}

Reduction of $\mathrm{Au}^{3+}$ ions was initiated by addition of $5 \mathrm{~mL}$ of GGLE and GGSE respectively to $95 \mathrm{~mL}$ of $10^{-3} \mathrm{M}$ aqueous $\mathrm{HAuCl}_{4} \cdot 3 \mathrm{H}_{2} \mathrm{O}$ solution in a $500 \mathrm{~mL}$ Erlenmeyer flask at $150 \mathrm{rpm}$ in the dark at $40^{\circ} \mathrm{C}$. Reduction of the $\mathrm{Au}^{3+}$ ions was monitored by measuring the UV-vis spectra of the solution at regular intervals on a spectrophotometer (SpectraMax M5, Molecular Devices Corporation, Sunnyvale, CA) operated at resolution of $1 \mathrm{~nm}$. Temperature optimization studies were carried out in water bath at $4-50^{\circ} \mathrm{C}$. Concentration optimization study was carried out by varying chloroauric acid in a range from 0.1-5 mM [21]. Effect of different halide ions like $\mathrm{Cl}^{-}, \mathrm{I}^{-}, \mathrm{Br}^{-}$and $\mathrm{F}^{-}$was estimated by carrying the reaction in presence of $10 \mathrm{mM}$ of $\mathrm{HCl}, \mathrm{HI}, \mathrm{HBr}$ and $\mathrm{HF}$ respectively.

Transmission electron microscopy (TEM), high resolution transmission electron microscopy (HRTEM) and dynamic light scattering (DLS) measurements

Surface morphology and particle size of bioreduced AuNPs were analyzed employing transmission electron microscopy (Tecnai 12 cryo TEM, FEI, Netherland) and JEOL-JEM-2100 higher resolution transmission electron microscopy (HRTEM). Energy dispersive spectra of AuNPs taken in the energy dispersive spectrometer (EDS) equipped in JEOL JSM 6360A analytical scanning electron microscope at an energy range $0-20 \mathrm{keV}$ confirmed the syntheses of AuNPs using GGLE as well as GGSE. Particle size analysis was carried out using the dynamic light scattering (Zetasizer Nano-2590, Malvern Instruments Ltd, Worcestershire, UK ) in polysterene cuvette [33].

\section{$\mathrm{X}$-ray diffraction (XRD) measurements}

The phase formation of bio-reduced AuNPs was studied with the help of XRD. The diffraction data of thoroughly dried thin films of nanoparticles on glass slides was recorded on D 8 Advanced Brucker X ray diffractometer with $\mathrm{Cu} \mathrm{Ka}(1.54 \AA)$ source. The crystallite size was calculated using Scherrer's formula $[22,34,35]$

$$
d=\frac{0.9 \lambda}{\beta \cos \theta}
$$

Here 0.9 is the shape factor, generally taken for a cubic system, $\lambda$ is the $\mathrm{x}$-ray wavelength, typically $1.54 \AA, \beta$ is the full width at half the maximum intensity (FWHM) in radians, and $\theta$ is the Bragg angle.

\section{Fourier transform infrared (FTIR) spectroscopy}

After complete bioreduction, AuNPs were washed by centrifugation at 10,000 rpm for $15 \mathrm{~min}$ at and redispersion in distilled water, which was repeated thrice. The purified pellet was dried and subjected to FTIR (Shimadzu IR Affinity) spectroscopy measurement using the potassium bromide $(\mathrm{KBr})$ pellet technique in the diffused reflection mode at a resolution of $4 \mathrm{~cm}^{-1}$. Au nanoparticle powder was mixed with $\mathrm{KBr}$ and subjected to IR source $500 \mathrm{~cm}^{-1}-4000 \mathrm{~cm}^{-1}$. Similar process was used for the FTIR study of GGLE and GGSE before and after bioreduction [22,33].

\section{Pulse radiolysis generated $\mathrm{ABTS}^{\bullet+}$ radical scavenging assay}

Pulse radiolysis was used to evaluate scavenging activity of AuNPs against $\mathrm{ABTS}^{++}$radical. $\mathrm{N}_{2} \mathrm{O}$ was purged in $4 \mathrm{~mL}$ of reaction mixture containing $0.05 \mathrm{M}$ sodium azide $\left(\mathrm{NaN}_{3}\right), 2 \mathrm{mM} \mathrm{2-2}$ '-azinobis 3-ethylbenzothioline-6-sulfonic acid (ABTS) and distilled water followed by exposure to an electron beam of pulse width $100 \mathrm{~ns}$ at a dose rate of $17.6 \mathrm{~Gy} /$ pulse. Scavenging of radiolytically generated $\mathrm{ABTS}^{*+}$ was estimated by recording the absorbance at $600 \mathrm{~nm}[36,37]$.

\section{Catalytic reduction of 4-nitrophenol}

$0.7 \mathrm{~mL}$ of freshly prepared $\mathrm{NaBH}_{4}(1.0 \mathrm{mM})$ was added to $1 \mathrm{~mL}$ of aqueous solution of 4-NP $(0.1 \mathrm{mM})$. The $\mathrm{pH}$ of solution was adjusted to 6.5 by using aqueous $1.0 \mathrm{M} \mathrm{NaOH}$. Aliquot amount of this solution was transferred to $3.0 \mathrm{~mL}$ quartz cuvette. The reaction was initiated by addition of $0.5 \mathrm{~mL}$ of aqueous suspension of AuNPs (1.0 mM). The progress of reaction was monitored by UV- visible spectroscopy recording a spectrum every $5 \mathrm{~min}$ in the range of 200-800 $\mathrm{nm}$ [33]

\section{Results}

\section{Synthesis and characterization of AuNPs}

UV-vis spectroscopy: Synthesis of AuNPs was monitored with the change in color and UV-vis spectroscopy. The reaction was started immediately after addition of GGLE into $1 \mathrm{mM}$ chloroauric acid. The color of the mixture instantly changed from yellow to purple and finally to ruby red (Figures $1 \mathrm{a}$ and $\mathrm{lb}$ ). The change in color is attributed to the collective oscillation of free conduction electrons induced by an interacting electromagnetic field in metallic nanoparticles known as surface plasmon resonance (SPR). Figure 2a shows the UV-vis spectra of AuNPs synthesized by GGLE as a function of reaction time. The SPR peak appeared immediately after the addition of GGLE and increased rapidly in intensity as a function of time with no significant peak shift (Figure 2a). This behavior indicates rapid bioreduction of $\mathrm{Au}^{3+}$ ions and thus a swift increase in the number of AuNPs. Although there was no significant synthesis in $2 \mathrm{~min}$, the reaction proceeded at a rapid rate from $4 \mathrm{~min}$. No significant difference between the intensity of SPR bands at $540 \mathrm{~nm}$ corresponding to 8 and 18 min showed that the reaction completed during the first $20 \mathrm{~min}$. This reaction is one of the most rapid reactions which have been reported in green synthesis

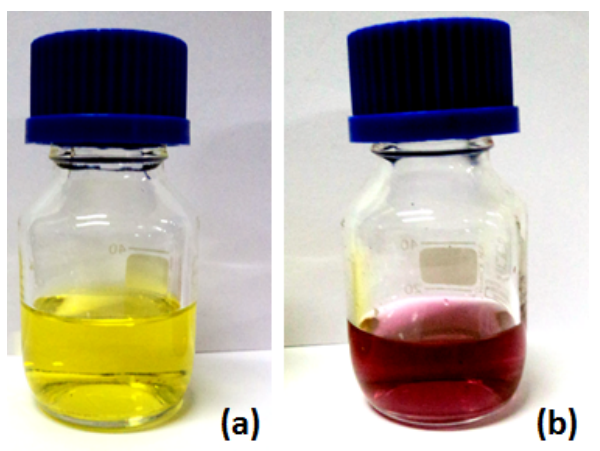

Figure 1: Visible colour change before and after bioreduction-(a) chloroauric acid (b) bioreduced AuNPs. 
Citation: Ghosh S, Patil S, Chopade NB, Luikham S, Kitture R, et al. (2016) Gnidia glauca Leaf and Stem Extract Mediated Synthesis of Gold Nanocatalysts with Free Radical Scavenging Potential. J Nanomed Nanotechnol 7: 358. doi:10.4172/2157-7439.1000358

of AuNPs at room temperature. Similarly, reduction of the $\mathrm{Au}^{3+}$ ions to AuNPs by GGSE could be followed by UV-vis spectroscopy. Although there was no significant change in the color of the reaction mixture after addition of GGSE till 6 min, a faint purple color emerged at 8 min that gradually developed into intense ruby red color which was stable even after 20 min which confirmed the synthesis of AuNPs. UV-vis spectra in Figure 2b recorded from the reaction mixture as a function of time using GGSE showed maximum absorbance at $540 \mathrm{~nm}$. The completion of synthesis of AuNPs within 20 min with both GGLE and GGSE indicated that the novel routes were not only environmentally benign but also extremely rapid.

The effect of concentration of chloroauric acid was investigated on AuNPs production by GGLE. A concentration of $1 \mathrm{mM}$ chloroauric acid was found to be optimum for achieving maximum synthesis of AuNPs. Further increase of concentration of chloroauric acid seemed to have no effect on the reaction rate. Similarly, concentrations lower than
$0.7 \mathrm{mM}$ were found to be less suitable for synthesis of AuNPs (Figures $3 \mathrm{a}$ and $3 \mathrm{~b}$ ). Notable variation in reaction rate was observed with time at different temperature as well. Higher temperatures facilitated the rate of synthesis of AuNPs. Synthesis increased significantly from $4^{\circ} \mathrm{C}$ to $50^{\circ} \mathrm{C}$. Figure 4a indicates instantaneous reduction of $\mathrm{Au}^{3+}$ to $\mathrm{Au}^{0}$ at $50^{\circ} \mathrm{C}$. Optimization studies with GGSE suggested that both concentration of chloroauric acid as well as reaction temperature plays a significant role in kinetics of the bioreduction. In case of concentration optimization initially $0.3 \mathrm{mM}$ of chloroauric acid showed a higher rate of synthesis while all other concentrations tested showed identical rate till $6 \mathrm{~min}$. thereafter a steady increase in the reaction rate was found with 0.5 and $0.7 \mathrm{mM}$ of chloroauric acid. However, as evident in Figure $3 \mathrm{~b}$, at the end of $20 \mathrm{~min}, 0.5 \mathrm{mM}$ was found to facilitate maximum synthesis of AuNPs employing GGSE. Rate of synthesis was found to remain unaffected at further higher concentrations of chloroauric acid. Similarly, it was observed that higher temperature facilitated the synthesis of AuNPs. The reaction failed to initiate at $4{ }^{\circ} \mathrm{C}$, while at $20^{\circ} \mathrm{C}$ the synthesis

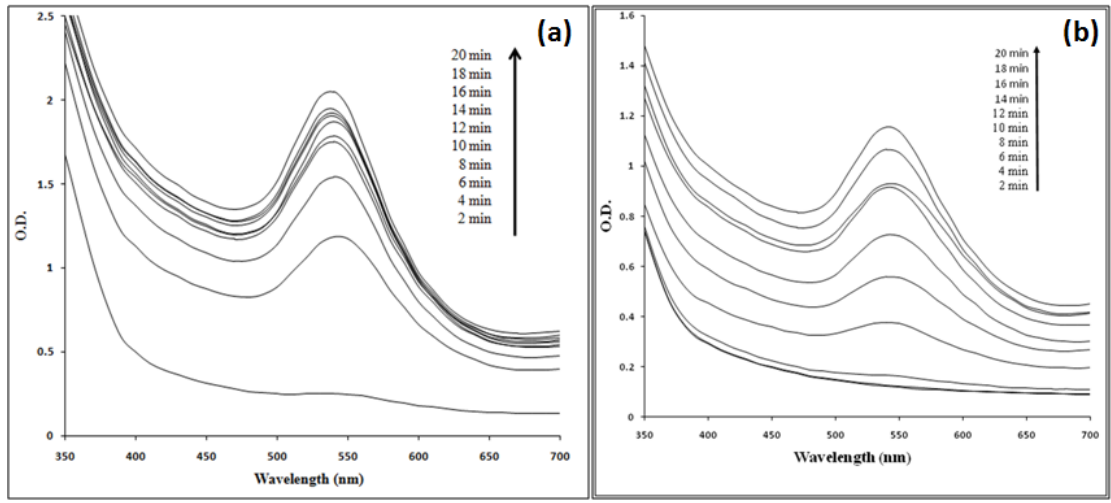

Figure 2: UV-vis spectra recorded as a function of reaction time of $1 \mathrm{mM} \mathrm{HAuCl} \cdot 3 \mathrm{H}_{2} \mathrm{O}$ solution with (a) GGLE and with GGSE at $40^{\circ} \mathrm{C}$.

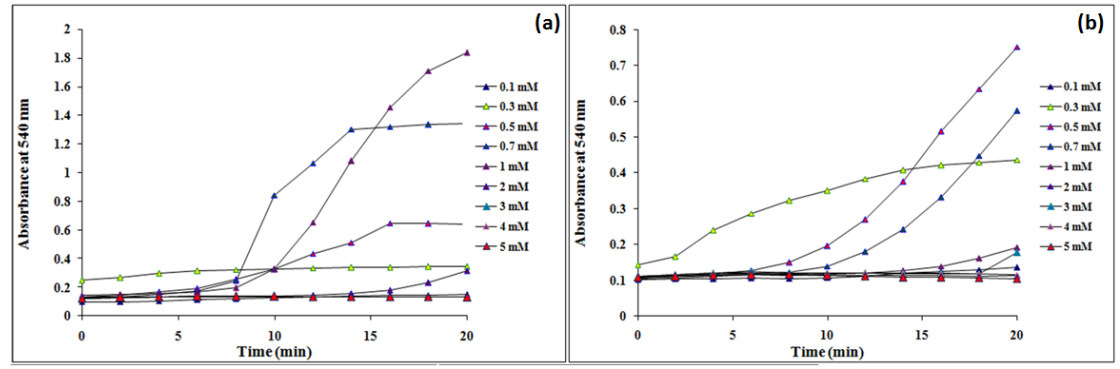

Figure 3: Time course of AuNPs formation obtained with different concentrations of $\mathrm{HAuCl}_{4} \cdot 3 \mathrm{H}_{2} \mathrm{O}$ using (a) GGLE and (b) GGSE at $40^{\circ} \mathrm{C}$.
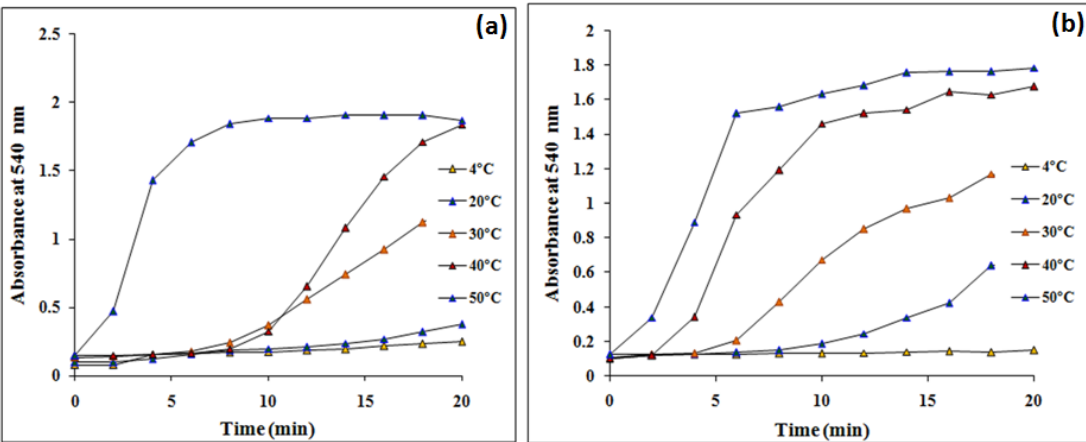

Figure 4: Time course of AuNPs formation obtained with $1 \mathrm{mM} \mathrm{HAuCl}_{4}$ using (a) GGLE (b) GGSE at different reaction temperature. 
Citation: Ghosh S, Patil S, Chopade NB, Luikham S, Kitture R, et al. (2016) Gnidia glauca Leaf and Stem Extract Mediated Synthesis of Gold Nanocatalysts with Free Radical Scavenging Potential. J Nanomed Nanotechnol 7: 358. doi:10.4172/2157-7439.1000358

Page 4 of 10

started after $8 \mathrm{~min}$. As the temperature was increased synthesis was expedited which was evidenced by initiation of synthesis after 6 min and $4 \mathrm{~min}$ at $30^{\circ} \mathrm{C}$ and $40^{\circ} \mathrm{C}$ respectively (Figure $4 \mathrm{~b}$ ). It is interesting to note that at higher temperature of $50^{\circ} \mathrm{C}$ the reaction initiated instantly after addition of GGSE into the chloroauric acid solution. A pronounced effect of various halide ions was noted on the rate of synthesis of the AuNPs employing GGLE. In case of $\mathrm{Cl}^{-}$ions the rate of synthesis was found to increase till 6 min after which stabilization was observed highlighting the maximum synthesis within 6 min (Figure $5 \mathrm{a})$. However, with $\mathrm{I}^{-}$ions the rate was found to be low. In presence of $\mathrm{Br}^{-}$ions a steady increase in the rate of synthesis was seen while in presence of $\mathrm{F}^{-}$ions the fastest rate achieving the maximum synthesis within almost 4 min was observed. Similar observation was noted even in case of synthesis of AuNPs employing GGSE in presence of various halide ions (Figure $5 \mathrm{~b}$ ). $\mathrm{F}^{-}$showed the highest rate of synthesis followed by $\mathrm{Cl}^{-}$and $\mathrm{Br}^{-}$while $\mathrm{I}^{-}$showed a low and steady reaction rate without any increase with time.
TEM, HRTEM and DLS measurements: Morphological analysis employing TEM exhibited pronounced polydispersity composed of exotic shapes such as spherical, triangular and hexagonal AuNPs. Majority of the AuNPs synthesized were spherical in shape and the larger particles were triangular in shape. It was observed that small spherical nanoparticles in range between 10 to $20 \mathrm{~nm}$ came together to adhere on to the larger spheres which are in range between 40 to $60 \mathrm{~nm}$ that finally adsorbed onto the triangles ranging between 100 to $300 \mathrm{~nm}$ (Figure 6). This is observed probably due to simultaneous merging of large number of nuclei over the surface of the seed particles in the early stage of the reaction which results in a layer of larger closely packed nanoparticles. Figure 7a shows the HRTEM micrographs of the small spherical nanoparticles while Figure $7 \mathrm{~b}$ shows both nanospheres and nanotriangles. Nanohexagon with distinct equilateral edges was evident in Figure 7c. Figure $7 \mathrm{~d}$ and $7 \mathrm{e}$ exhibits the bright field TEM and STEM images for the triangular nanoparticles, while Figure $7 f$ confirmed that the nanotriangles were of elemental gold. Formation of
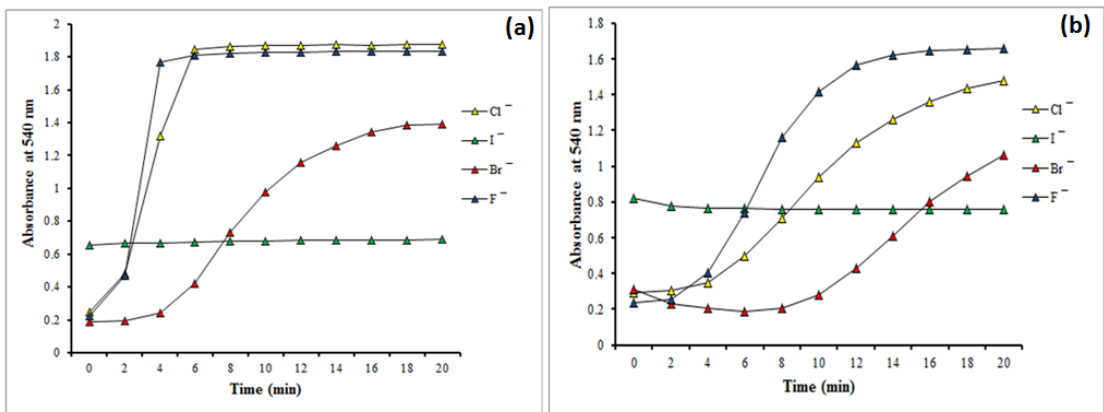

Figure 5: Time course of AuNPs formation obtained with $1 \mathrm{mM} \mathrm{HAuCl} 4 \cdot 3 \mathrm{H}_{2} \mathrm{O}$ using (a) GGLE (b) GGSE in presence of different halide ions.

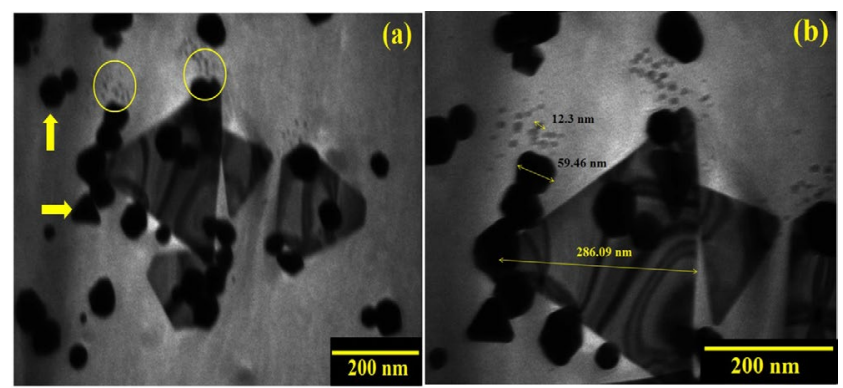

Figure 6: Characterization of AuNPs formed with $1 \mathrm{mM} \mathrm{HAuCl} .3 \mathrm{H}_{\mathrm{O}} \mathrm{O}$ and $5 \% \mathrm{GGLE}$ at $40^{\circ} \mathrm{C}$ by transmission electron microscopy (TEM). (a) Adherence of spherical nanoparticles to the gold nanotriangles; (b) AuNPs of variable size adsorbed on surface of triangles. The inset bars represent $200 \mathrm{~nm}$.

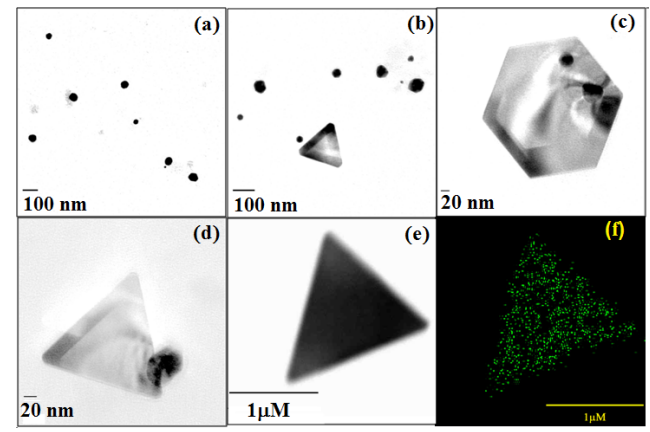

Figure 7: Characterization of AuNPs formed with $1 \mathrm{mM} \mathrm{HAuCl} \cdot 3 \mathrm{H}_{2} \mathrm{O}$ and $5 \% \mathrm{GGLE}$ at $40^{\circ} \mathrm{C}$ by high resolution transmission electron microscopy (HRTEM). (a) Small spherical AuNPs; (b) Spherical and triangular; (c) Gold nanohexagon equilateral edges; (d) Gold nanotriangles; (e) Scanning transmission mode micrographs for gold nanotriangle; (f) Elemental mapping of gold nanotriangle. 
Citation: Ghosh S, Patil S, Chopade NB, Luikham S, Kitture R, et al. (2016) Gnidia glauca Leaf and Stem Extract Mediated Synthesis of Gold Nanocatalysts with Free Radical Scavenging Potential. J Nanomed Nanotechnol 7: 358. doi:10.4172/2157-7439.1000358

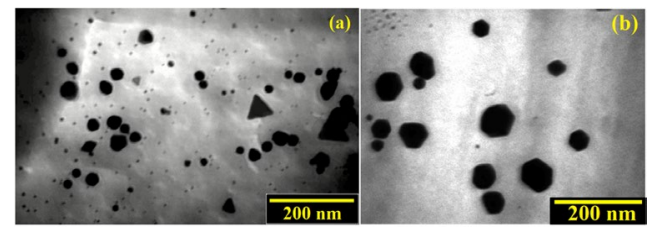

Figure 8: Characterization of AuNPs formed with $1 \mathrm{mM} \mathrm{HAuCl}{ }_{4} \cdot 3 \mathrm{H}_{2} \mathrm{O}$ and $5 \%$ GGSE at $40^{\circ} \mathrm{C}$ by transmission electron microscopy (TEM). (a) Anisotropic gold nanotriangles; (b) Gold nanohexagons. The inset bars represent $200 \mathrm{~nm}$.

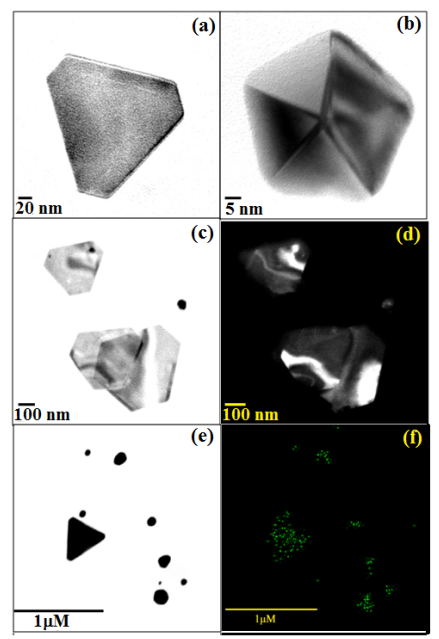

Figure 9: Characterization of AuNPs formed with $1 \mathrm{mM} \mathrm{HAuCl} .3 \mathrm{H}_{2} \mathrm{O}$ and $5 \% \mathrm{GGSE}$ at $40^{\circ} \mathrm{C}$ by high resolution transmission electron microscopy (HRTEM). (a) Gold nanotrapezoid; (b) Pentagonal pyramidal nanoparticle; (c) Gold nanohexagon adhered to each other; (d) Dark field TEM images of adhered nanohexagons; (e) Scanning transmission mode micrographs for gold nanoanisotrops revealing triangles and spheres; (f) Elemental mapping of anisotropic AuNPs.

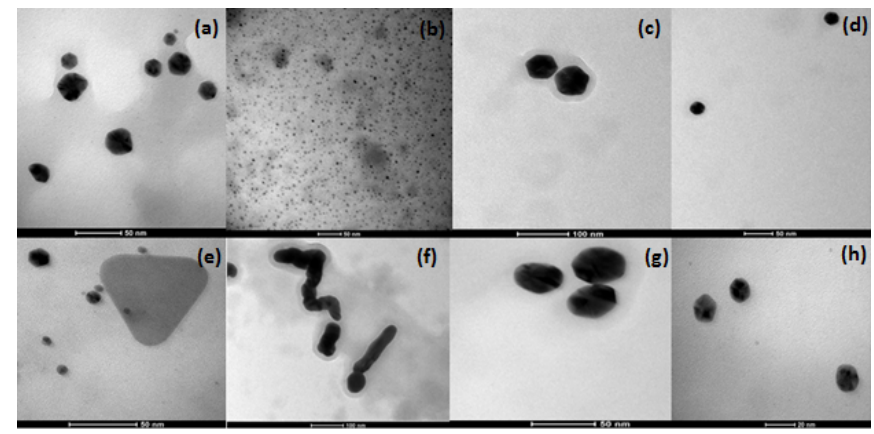

Figure 10: TEM micrographs of AuNPs formed in presence of various halide ions. AuNPs synthesized by GGLE in presence of (a) $\mathrm{Cl}^{-}$, (b) $\mathrm{I}^{-}$, (c) $\mathrm{Br}^{-}$, (d) $\mathrm{F}^{-}$. AuNPs synthesized by GGSE in presence of $(\mathrm{e}) \mathrm{Cl}^{-}$, (f) $\mathrm{I}^{-},(\mathrm{g}) \mathrm{Br}^{-},(\mathrm{h}) \mathrm{F}^{-}$.

these gold nanotriangles might be attributed owing to the chloride ions in the reaction mixtures.

The morphology and size of AuNPs synthesized by GGSE determined by TEM analysis is shown in Figure 8 . The particles formed were anisotropic in nature. Majority of the synthesized AuNPs were spherical which were of different size ranging from 5 to $200 \mathrm{~nm}$. Apart from spheres and triangles particles of exotic shape like trapezoids and hexagons were also found among the mixed population of the bioreduced AuNPs. Particles formed were found to be well dispersed and no agglomeration was observed. HRTEM was employed to visualize the morphology of very small nanoparticles. Discrete trapezoid and pentagon with elevated faces (Figure 9a and 9b) were spotted that was remarkable and limits any report earlier. Both light and dark field TEM micrographs in Figure 9c-9e respectively, showed back to back adherence of nanohexagons. Elemental mapping in Figure 9f confirmed the presence of elemental gold.

TEM micrographs of AuNPs synthesized by GGLE in presence of various halide ions showed unique morphological features (Figure 10). AuNPs synthesized by GGLE in presence of $\mathrm{Cl}^{-}$ions showed irregular to approximately spherical shape between 18 to $35 \mathrm{~nm}$. It is important to note that in presence of $\mathrm{I}^{-}$ions the nanoparticles of very small size ranging 2 to $7 \mathrm{~nm}$ was synthesized. $\mathrm{Br}^{-}$ions could lead to the synthesis of hexagonal nanoparticles of larger size between 70 to $80 \mathrm{~nm}$. $\mathrm{F}^{-}$ions gave perfectly spherical nanoparticles between 20 to $35 \mathrm{~nm}$ in majority. In case of GGSE anisotropic nanoparticles were synthesized in presence of $\mathrm{Cl}^{-}$ions. It is important to note that gold nanowire like structures were observed with $\mathrm{I}^{-}$ions while roughly hexagonal with blunt aged nanoparticles were synthesized in presence of $\mathrm{Br}^{-}$ions. 
Citation: Ghosh S, Patil S, Chopade NB, Luikham S, Kitture R, et al. (2016) Gnidia glauca Leaf and Stem Extract Mediated Synthesis of Gold Nanocatalysts with Free Radical Scavenging Potential. J Nanomed Nanotechnol 7: 358. doi:10.4172/2157-7439.1000358

Page 6 of 10

Mostly spherical nanoparticles could be synthesized in presence of the $\mathrm{F}^{-}$ions.

Further analysis of the AuNPs by energy dispersive spectroscopy in Figure 11a and $11 \mathrm{~b}$ confirmed the presence of signature signal characteristic of elemental gold. Particle size distribution of AuNPs shown in Figure 12a showed that most of the AuNPs synthesized by GGLE were in size between $10 \mathrm{~nm}$ to $20 \mathrm{~nm}$. However, larger nanoparticles between 100 to $200 \mathrm{~nm}$ were also evident which can be well correlated with the TEM observations. Similarly, particle size analysis of AuNPs synthesized by GGSE, employing DLS confirmed that the majority of the particles were between 11 to $15 \mathrm{~nm}$ (Figure $12 b)$.

XRD analysis: The obtained powder X ray diffraction data for GGLE and GGSE synthesized AuNPs were compared with the standard data from JCPDS (Joint Committee for Powder Diffraction Standard). This data matched with the standard JCPDS card no. 05-0784 confirming crystalline cubic phase of the sample with lattice constant $\mathrm{a}=4.078 \AA$. Four peaks from in the increasing order of $2 \theta$ correspond to the lattice planes (111), (200), (220) and (311) respectively (Figure 13a and 13b). Purity of AuNPs was confirmed owing to absence of other unassigned peaks. Peak broadening represent smaller particle size. The inset shows peak broadening of the highest intensity peak corresponding to (111) plane. The crystallite size of AuNPs synthesized by GGLE and GGSE was calculated to be $\sim 10$ and $15 \mathrm{~nm}$, respectively.

FTIR analysis: The chemistry of GGLE and GGSE before and after bioreduction were studied with the help of FTIR spectroscopy. Dried samples were added to $\mathrm{KBr}$ powder and the FTIR data was recorded on Shimadzu IRAffinity. Figure 14a shows the FTIR data of GGLE before and after bioreduction of chloroauric acid to AuNPs. Major peaks to

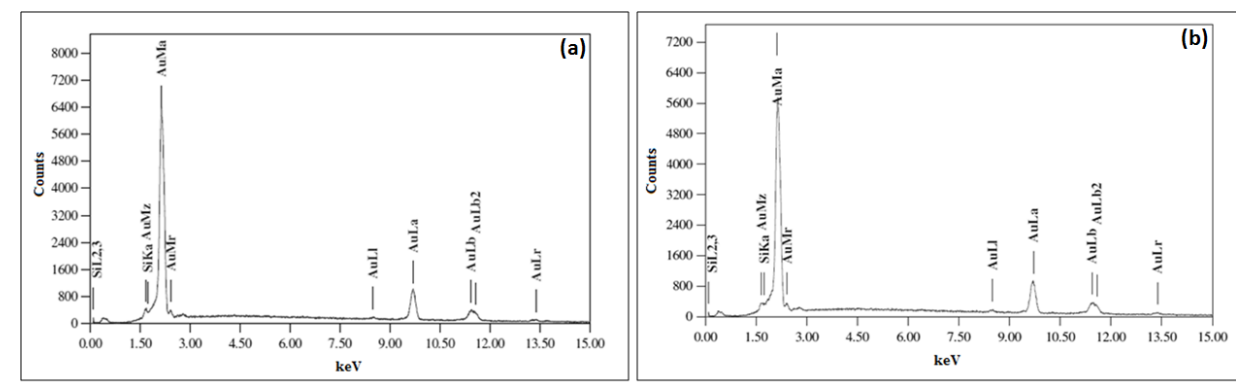

Figure 11: Representative spot EDS profile confirming the synthesis of AuNPs by (a) GGLE and (b) GGSE.
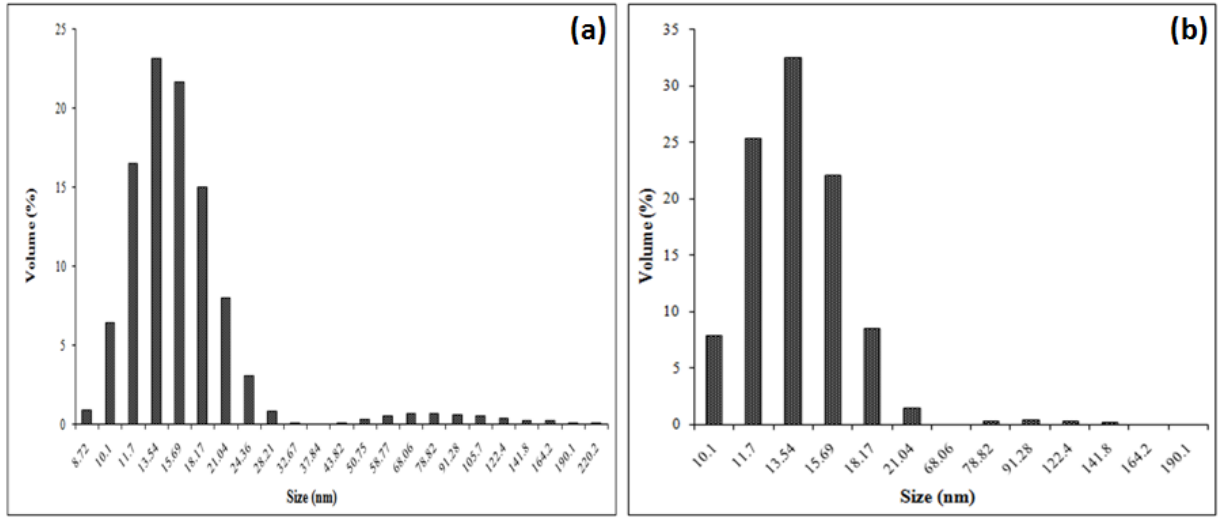

Figure 12: A histogram of size distribution of AuNPs synthesized by (a) GGLE and (b) GGSE.
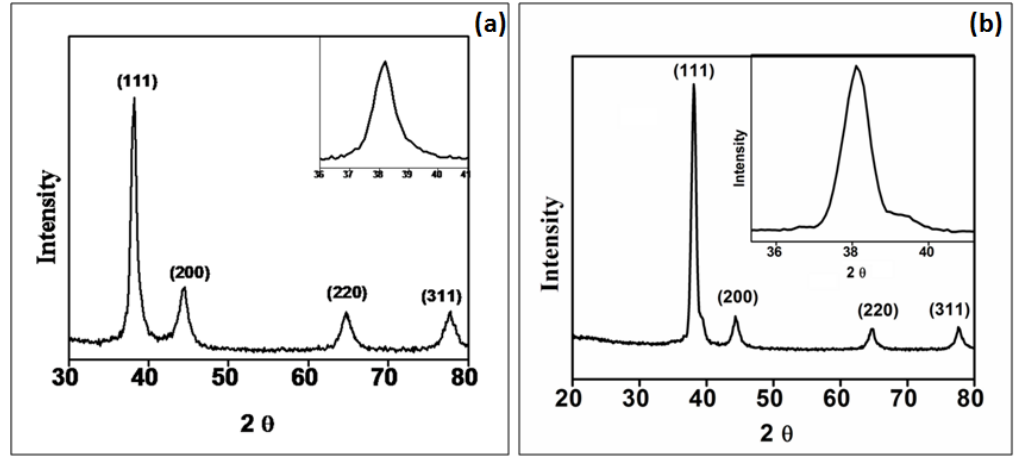

Figure 13: Representative XRD profile of thin film AuNPs synthesized by (a) GGLE and (b) GGSE. 
Citation: Ghosh S, Patil S, Chopade NB, Luikham S, Kitture R, et al. (2016) Gnidia glauca Leaf and Stem Extract Mediated Synthesis of Gold Nanocatalysts with Free Radical Scavenging Potential. J Nanomed Nanotechnol 7: 358. doi:10.4172/2157-7439.1000358

Page 7 of 10

be considered in the spectra were $3300,2929,1395,1251,1068 \mathrm{~cm}^{-1}$. GGLE showed a strong peak at $\sim 3300 \mathrm{~cm}^{-1}$ which is a characteristic of hydroxyl group in alcoholic and phenolic compound. Peak at 2929 $\mathrm{cm}^{-1}$ corresponds to $\mathrm{C}-\mathrm{H}$ stretch. Also the remaining peaks at 1395 and $1251 \mathrm{~cm}^{-1}$ were attributed to methyl group, whereas peak at 1068 $\mathrm{cm}^{-1}$ refers to C-O. A notable change in the position of O-H peak was observed before and after bioreduction. This peak is seen to be shifted after bioreduction, indicating bonding of the extract through phenolic O-H group. A similar pattern was observed even in case of GGSE as well (Figure 14b). Unaltered peaks present both before and after synthesis indicates the probable stabilizing property of the extract, coating the AuNPs and thereby itself remaining unchanged. A notable change was observed where the intensity of peak at $1611 \mathrm{~cm}^{-1}$, corresponding to $\mathrm{C}=\mathrm{C}$ bond in benzene ring was lowered.

Scavenging of $\mathrm{ABTS}^{\circ+}$ radicals generated by pulse radiolysis: It was observed that the AuNPs synthesized by GGSE could show higher scavenging activity against $\mathrm{ABTS}^{\cdot+}$ radicals with a second order rate constant of $1.78 \times 10^{7}$ (Figure 15). However the scavenging activity in case of the AuNPs synthesized by GGLE was found to be slightly lower with a second order rate constant of $1.31 \times 10^{7}$. Thus it was found that the bioreduced AuNPs can act as potent antioxidants by scavenging of free radicals.

Catalytic activity: After addition of $\mathrm{NaBH}_{4}$, the absorption of 4-NP undergoes red shift from 317 to $400 \mathrm{~nm}$ due to formation of 4-nitrophenolate anion under alkaline condition that can be monitored spectrophotometrically. Reduction of $-\mathrm{NO}_{2}$ group is possible only after the addition of catalytic amount of AuNPs. The addition of AuNPs to the solution causes a decrease in peak intensity at $400 \mathrm{~nm}$ peak with appearance of a new peak at around $300 \mathrm{~nm}$ which was attributed due to the synthesis of 4-AP as shown in Figure 13a and 13b. The reactions followed pseudo-first order rate kinetics as the concentration of

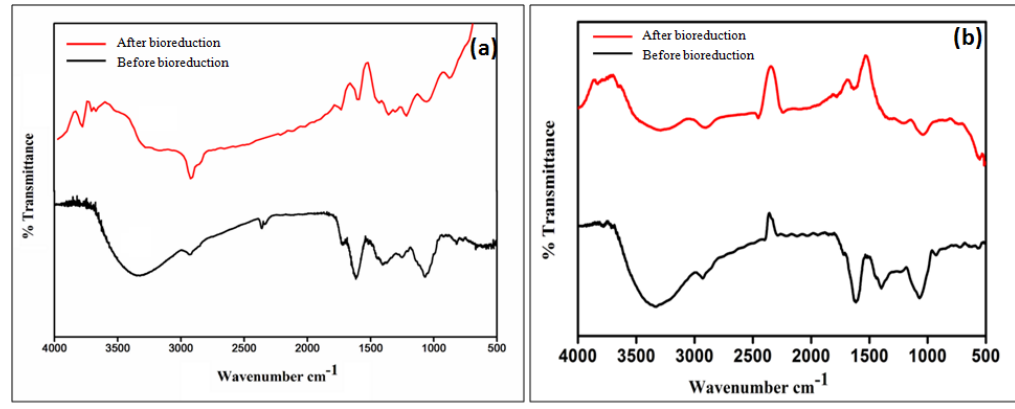

Figure 14: FTIR absorption spectra of dried (a) GGLE and (b) GGSE before and after complete bioreduction of chloroaurate ions at $50^{\circ} \mathrm{C}$

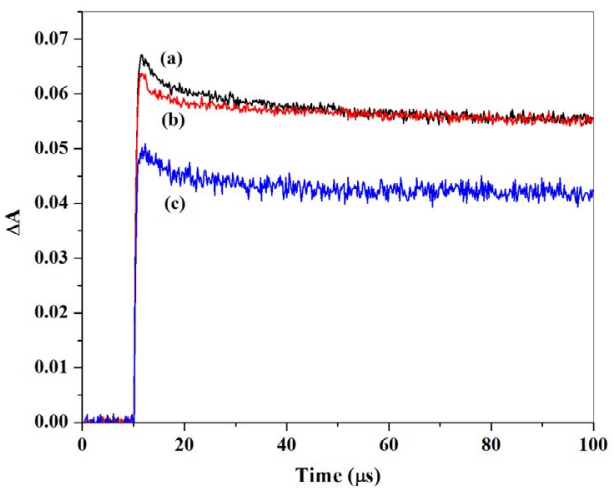

Figure 15: Pulse radiolysis generated $A B T S^{++}$radical scavenging by AuNPs synthesized by (a) control (b) GGSE, (c) GGLE.

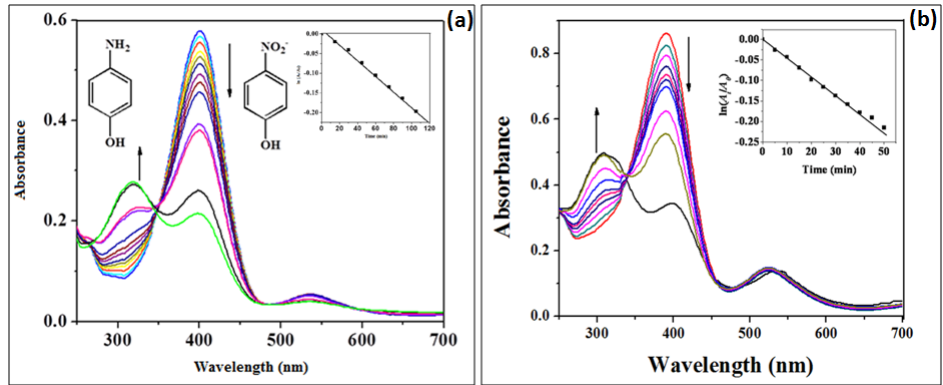

Figure 16: Time dependent UV-vis spectra for monitoring 4-nitrophenol reduction by $\mathrm{NaBH}_{4}$ catalyzed by AuNPs synthesized by GGLE and GGSE. The inset shows the plot indicating the variation of $\ln \left(A_{t} / A_{0}\right)$ vs. time. 


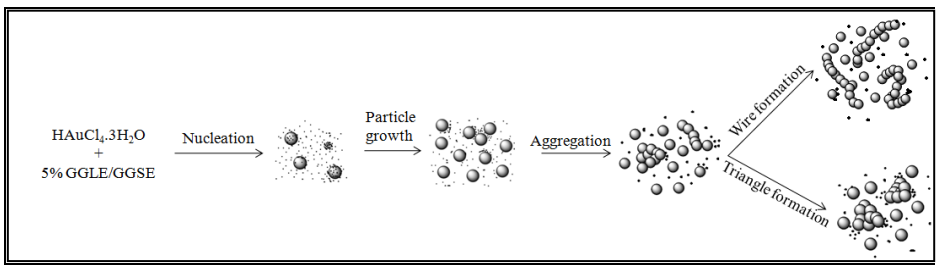

Figure 17: Schematic illustration of the growth mechanism of AuNPs by reduction of $\mathrm{Au}^{3+}$ with GGLE and GGSE.

$\mathrm{NaBH}_{4}$ used exceeded that of 4-NP and the AuNPs. Thus, a good linear correlation was obtained between $\ln \left(A_{t} / A_{0}\right)$ vs time as seen in (Figure $16 \mathrm{a}$ and $16 \mathrm{~b})\left(A_{t}\right.$ : absorbance at $400 \mathrm{~nm}$ at time $t, A_{0}$ : absorbance at $400 \mathrm{~nm}$ at $t=0)$. The apparent rate constant $(k)$ determined from this plot was $1.99 \times 10^{-3} \mathrm{~min}^{-1}$ and $4.498 \times 10^{-3} \mathrm{~min}^{-1}$, for GGLE and GGSE synthesized AuNPs, respectively. Thus it was evident that the AuNPs bioreduced by GGLE and GGSE possessed a strong catalytic potential.

\section{Discussions}

The promising potential of AuNPs in both field of chemistry and the medicine have augmented the greater interests to investigate novel eco-friendly rapid routes to achieve shape tuned AuNPs with both medico-chemical importance.

In this study synthesis of AuNPs was achieved employing aqueous extracts of leaf and stem of a traditional medicinal plant, Gnidia glauca. Development of ruby red color with a maximum absorbance at $540 \mathrm{~nm}$ within $20 \mathrm{~min}$ suggested that the process is one of the rapid mode of biological synthesis of AuNPs [23,38]. It was found to be faster as compared to the synthesis of AuNPs using Mentha piperita and Cacumen platycladi which took $2 \mathrm{~h}$ and 90 min respectively for complete reduction $[39,40]$ However it was comparable to Cassia auriculata which is reported to take $10 \mathrm{~min}$ for completion of synthesis of AuNPs [41]. Optimization studies revealed that the rate of reaction could be increased with rise in temperature. Shankar et al, also mentioned the increase of reduction rate with increase in reaction temperature for synthesis of AuNPs employing lemongrass [42]. Thus our results are in concurrence with earlier reports where increase in temperature has shown pronounce effect in enhancement of reduction $[43,44]$. A significant variation was also observed in the rate of synthesis with variation in the concentration of the chloroauric acid. TEM micrographs showed that GGLE and GGSE could synthesize AuNPs of exotic shapes like nanotriangles, hexagons and spheres which is well in agreement with the previous reports [21,22,25,45].

The nanoprisms formed possess high surface energy which suffers a shrinking process in order to reduce the surface energy to a minimum level which might have resulted in the formation of the blunt-angled nanoprisms [24]. Gardea-Torresdey et al, reported that the AuNPs formed within the live alfalfa plant were in range of 2-20 nm and the variation in size was a result of formation of nanoparticles at different times [46]. On the other hand, it is reported that on evaporation of the solvent, capillary forces draw the nanospheres together followed by which they crystallize into a hexagonally closed packed pattern [47]. The most significant observation in the TEM micrograph was the real time images of Ostwalds ripening in case of the synthesis and shape evolution of spherical AuNPs to triangles (Figure 17). It is reported that in Ostwald ripening, smaller particles dissolve preferentially with subsequent crystallization onto larger particles, which involves nucleation and growth processes of larger particles from smaller ones [48]. Equilateral nanotriangles observed might be due to the halide ions in the reaction mixture as mentioned earlier [43]. Similar results obtained by Kumar et al, where AuNPs were synthesized employing an antidiabetic plant, Cassia auriculata thus provides strong rationale for synthesis of AuNPs by G. glauca, which we have recently reported as a potent antidiabetic plant $[29,41]$.

It is important to note that halogen ions play an important role in modulating the shape of metal nanoparticles $[43,45]$. Effect of various halide ions was found to be noteworthy and thus can be considered to be one of the most significant parameters for shape tunable biological synthesis. Although $\mathrm{Cl}^{-}$ions showed polydispersity to some extent, $\mathrm{I}^{-}$ions showed considerable impact on the shape of the bioreduced nanoparticles. In case of GGLE the nanoparticles synthesized were very small in size and they were found to be well dispersed without any agglomeration. On the other hand synthesis of gold nanowires in case of GGSE signifies the aggregation of the thermodynamically unstable gold nuclei due to their small size. Additionally the lower surface energy of larger particles as compared to that of smaller ones facilitates them to grow onto larger ones by joining together because of their Brownian motion in the solution, forming wire-like structures [49]. The formation of these nanowires can be well correlated to the Ostwald ripening due to the collision and join between small nanoparticles $[48,50]$.

FTIR analysis clearly revealed that the hydroxyl groups corresponding to the phenolics and flavonoids present in the extracts might play a key role in the synthesis and stabilization of the AuNPs [24,35,51]. Biogenic AuNPs showed an efficient ABTS $^{++}$radical scavenging activity which marks its promises as potent antioxidants which is in well agreement with the recent report on the synthesis of AuNPs and AgNPs employing Prunus armeniaca fruit extract [52]. Bioreduced AuNPs exhibited catalytic potential similar to gold and silver synthesized by Breynia rhamnoides which followed the pseudofirst-order kinetics as well during catalytic reduction of 4-NP [53]. Panigrahi et al has concluded in detail that such catalytic behavior of AuNPs largely depends on the size and shape of the nanoparticles [54].

Thus, this rapid and heat independent clean, nontoxic biosynthesis of AuNPs can be considered as one of the most efficient approach for formulating nanoparticles reported till date which indicates it's potential for various commercial applications $[23,55,56]$.

\section{Conclusions}

In summary, we have demonstrated the potential of GGLE and GGSE in rapid synthesis of AuNPs. This is the first report on GGLE and GGSE mediated syntheses of AuNPs and the uniqueness of the methodology lie in rapid reaction rate completing the syntheses within $20 \mathrm{~min}$. The conditions were optimized in order to achieve maximum synthesis of AuNPs. Optimization studies revealed that concentration of chloroauric acid and temperature played a key role in controlling the rate of synthesis. Bioreduced nanoparticles were anisotropic that varied within a size range of 10 to $300 \mathrm{~nm}$ that was confirmed by 
Citation: Ghosh S, Patil S, Chopade NB, Luikham S, Kitture R, et al. (2016) Gnidia glauca Leaf and Stem Extract Mediated Synthesis of Gold Nanocatalysts with Free Radical Scavenging Potential. J Nanomed Nanotechnol 7: 358. doi:10.4172/2157-7439.1000358

particle size analysis employing dynamic light scattering. Furthermore, catalytic studies performed for conversion of 4-NP to 4-AP indicated the catalytic potential of biogenic AuNPs supporting its industrial applications.

\section{Acknowledgment}

S. Ghosh thanks Council of Scientific and Industrial Research (CSIR, Government of India) for Senior Research Fellowship (09/137(0516)/2012-EMR-I). We acknowledge financial support from UPE Phase II for 2012-2017 by UGC New Delhi, India. The authors acknowledge use of TEM facilities in Chemical Engineering and CRNTS funded by the DST through Nanomission and IRPHA schemes. Authors are thankful to Dr. M. Jayakannan of Indian Institute of Science Education and Research (IISER), Pune- 411021, India for DLS facility.

\section{References}

1. Ghosh S, More P, Nitnavare R, Jagtap S, Chippalkatti R, et al. (2015) Antidiabetic and antioxidant properties of copper nanoparticles synthesized by medicinal plant Dioscorea bulbifera. J Nanomed Nanotechnol S6: 007

2. Ghosh S, Nitnavare R, Dewle A, Tomar GB, Chippalkatti R, et al. (2015) Novel platinum-palladium bimetallic nanoparticles synthesized by Dioscorea bulbifera: anticancer and antioxidant activities. Int J Nanomed 10: 1-4.

3. Shedbalkar U, Singh R, Wadhwani S, Gaidhani S, Chopade BA (2014) Microbial synthesis of gold nanoparticles: current status and future prospects. Adv Colloid Interface Sci 209: 40-48.

4. Singh R, Shedbalkar UU, Wadhwani SA, Chopade BA (2015) Bacteriagenic silver nanoparticles: synthesis, mechanism, and applications. Appl Microbiol Biotechnol 99: 4579-459

5. Wadhwani SA, Shedbalkar UU, Singh R, Chopade BA, et al. (2016) Biogenic selenium nanoparticles: current status and future prospects. Appl Microbiol Biotechnol 100: 2555-2566.

6. Ghosh S, Jagtap S, More P, Shete UJ, Maheshwari NO, et al. (2015) Dioscorea bulbifera mediated synthesis of novel $\mathrm{Au}$ core $\mathrm{Ag}$ shell nanoparticles with potent antibiofilm and antileishmanial activity. J Nanomater.

7. Kitture R, Ghosh S, More PA, Date K, Gaware S, et al. (2015) CurcuminLoaded, Self-Assembled Aloevera Template for Superior Antioxidant Activity and Trans-Membrane Drug Release. J Nanosci Nanotechnol 15: 409-4045.

8. Kitture R, Chordiya K, Gaware S, Ghosh S, More PA, et al. (2015) ZnO Nanoparticles-Red Sandalwood Conjugate: A Promising Anti-Diabetic Agent. J Nanosci Nanotechnol 15: 4046-4051.

9. Adersh A, Kulkarni A R, Ghosh S, More P, Chopade B A, et al. (2015) Surface defect rich $\mathrm{ZnO}$ quantum dots as antioxidant inhibiting a-amylase and a-glucosidase: A potential anti-diabetic nanomedicine. J Mater Chemi B 3: $4592-4606$

10. Mallick A, More P, Ghosh S, Chippalkatti R, et al. (2015) Dual drug conjugated nanoparticle for simultaneous targeting of mitochondria and nucleus in cance cells. ACS Appl Mater Interfaces 7: 7584-7598.

11. Ghosh S, More P, Derle A, Kitture R, Kale T, et al. (2015) Diosgenin Functionalized Iron Oxide Nanoparticles as Novel Nanomaterial Against Breast Cancer. J Nanosci Nanotechnol 15: 9464-9472.

12. Kitture R, Ghosh S, Kulkarni P, Liu XL, Maity D, et al. (2012) FeO4citratecurcumin: Promising conjugates for superoxide scavenging, tumor suppression and cancer hyperthermia. J Appl Phys 111: 064702.

13. Salunke GR, Ghosh S, Kumar RJS, Khade S, Vashisth P, et al. (2014) Rapid efficient synthesis and characterization of AgNPs, AuNPs and AgAuNPs from a medicinal plant, Plumbago zeylanica and their application in biofilm control. Int J Nanomedicine 9: 265-265.

14. Sant DG, Gujarathi TR, Harne SR, Ghosh S, Kitture R, et al. (2013) Adiantum philippense $\mathrm{L}$. frond assisted rapid green synthesis of gold and silve nanoparticles. Journal of Nanoparticles 2031: 1-9.

15. Singh R, Nawale LU, Arkile M, Shedbalkar UU, Wadhwani SA, et al. (2015) Chemical and biological metal nanoparticles as antimycobacterial agents: A comparative study. Int J Antimicrob Agents 46: 18-188.

16. Deshpande P, Gaidhani S, Hitendra M, Shouche $Y$, Narhe R, et al. (2015) Biosynthesis of gold nanoparticles by human microbiota from healthy skins. $J$ Nanomed Nanotechnol 6: 4
17. Gaidhani SV, Yeshvekar RK, Shedbalkar UU, Bellare JH, Chopade BA (2014) Bio-reduction of hexachloroplatinic acid to platinum nanoparticles employing Acinetobacter calcoaceticus. Process Biochem 49: 2313-2319.

18. Wadhwani SA, Shedbalkar UU, Singh R, Karve MS, Chopade BA (2014) Novel polyhedral gold nanoparticles: green synthesis, optimization and characterization by environmental isolate of Acinetobacter sp. SW0. World J Microbiol Biotechnol 0: 272-271.

19. Gaidhani S, Singh R, Singh D, Patel U, Shevade K, (2013) Biofilm disruption activity of silver nanoparticles synthesized by Acinetobacter calcoaceticus PUCM 1005. Mater Lett 108: 324-327.

20. Singh R, Wagh P, Wadhwani S (2013) Synthesis, optimization, and characterization of silver nanoparticles from Acinetobacter calcoaceticus and their enhanced antibacterial activity when combined with antibiotics. Int Nanomed 8: 4277-4290.

21. Ghosh S, Patil S, Ahire M, Kitture R, Kale S, et al. (2012) Synthesis of silver nanoparticles using Dioscorea bulbifera tuber extract and evaluation of its synergistic potential in combination with antimicrobial agents. Int $J$ Nanomedicine 7: 48-496

22. Ghosh S, Patil S, Ahire M, Kitture R, Kale S, et al. (2012) Synthesis of silver nanoparticles using Dioscorea bulbifera tuber extract and evaluation of its synergistic potential in combination with antimicrobial agents. Int $J$ Nanomedicine 7: 48-496.

23. Shankar SS, Rai A, Ahmad A, Sastry M (2004) Rapid synthesis of Au, Ag, and bimetallic Au core-Ag shell nanoparticles using Neem (Azadirachta indica) lea broth. J Colloid Interface Sci 275: 496-502.

24. Huang J, Li Q, Sun D, Lu Y, Su Y, et al. (2007) Biosynthesis of silver and gold nanoparticles by novel sundried Cinnamomum camphora leaf. Nanotechnology 18: $105104-105114$

25. Smitha SL, Philip D, Gopchandran KG (2009) Green synthesis of gold nanoparticles using Cinnamomum zeylanicum leaf broth. Spectrochim Acta A Mol Biomol Spectrosc 74: 75-79.

26. Golmoraj VE, Khoshayand MR, Amini M, Moghadamd KM, Amin G, et al. (2011) The surface chemistry and stability of gold nanoparticles prepared using methanol extract of Eucalyptus camaldulensis. J Exp Nanosci 6: 200-208.

27. Philip D, Unni C, Aromal SA, Vidhu VK (2011) Murraya Koenigii leaf-assisted rapid green synthesis of silver and gold nanoparticles. Spectrochim Acta A Mo Biomol Spectrosc 78: 899-904.

28. Ghosh S, Parihar VS, Dhavale DD, Chopade BA (2015) Commentary on therapeutic potential of Gnidia glauca: A novel medicinal plant. Med Chem 5 351-353.

29. Ghosh S, Ahire M, Patil S, Jabgunde A, Bhat Dusane M, et al. (2012) Antidiabetic Activity of Gnidia glauca and Dioscorea bulbifera: Potent Amylase and Glucosidase Inhibitors. Evid Based Complement Alternat Med 2012 929051.

30. Saha S, Pal A, Kundu S, Basu S, Pal T (2010) Photochemical green synthesis of calcium-alginate-stabilized $\mathrm{Ag}$ and $\mathrm{Au}$ nanoparticles and their catalytic application to 4-nitrophenol reduction. Langmuir 26: 2885-289.

31. Pradhan N, Pal A, Pal T (2002) Silver nanoparticle catalyzed reduction of aromatic nitro compounds. Colloids Surf A Physicochem Eng Asp 196: $247-$ 257.

32. Pfaff A, Shinde VS, Lu Y, Wittemann A, Ballauff M, et al. (2011) Glycopolymergrafted polystyrene nanospheres. Macromol Biosci 11: 199-210.

33. Ghosh S, Patil S, Ahire M, Kitture R, Gurav DD, et al. (2012) Gnidia glauca flower extract mediated synthesis of gold nanoparticles and evaluation of its chemocatalytic potential. J Nanobiotechnology 10: 17.

34. Dubey SP, Lahtinen M, Sillanpää M (2010) Tansy fruit mediated greener synthesis of silver and gold nanoparticle. Process Biochem 45: 1065-1071.

35. Narayanan KB, Sakthivel N (2008) Coriander leaf mediated biosynthesis of gold nanoparticles. Mater Lett 62: 4588-4590.

36. Patil AB, Ghosh S, Phadatare SD, Pathak P, Sharma GK, et al. (2015) Evaluation of malonic acid diamide analogues as radical scavenging agents. New Journal of Chemistry 9: 1267-127.

37. Ghosh S, Derle A, Ahire M, More P, Jagtap S, et al. (201) Phytochemical analysis and free radical scavenging activity of medicinal plants Gnidia glauca and Dioscorea bulbifera. PLoS One 8: e82529. 
Citation: Ghosh S, Patil S, Chopade NB, Luikham S, Kitture R, et al. (2016) Gnidia glauca Leaf and Stem Extract Mediated Synthesis of Gold Nanocatalysts with Free Radical Scavenging Potential. J Nanomed Nanotechnol 7: 358. doi:10.4172/2157-7439.1000358

38. Wang Y, He X, Wang K, Zhang X, Tan W (2009) Barbated Skullcup herb extract-mediated biosynthesis of gold nanoparticles and its primary application in electrochemistry. Colloids Surf B Biointerfaces 7: 75-79.

39. MubarakAli D, Thajuddin N, Jeganathan K, Gunasekaran M (2011) Plant extract mediated synthesis of silver and gold nanoparticles and its antibacterial activity against clinically isolated pathogens. Colloids Surf B Biointerfaces 85 $60-65$

40. Zhan G, Huang J, Lin L, Lin W, Emmanuel K, et al. (2011) Synthesis of gold nanoparticles by Cacumen platycladi leaf extract and its simulated solution: toward the plant-mediated biosynthetic mechanism. J Nanopart Res 1: $4957-$ 4968.

41. Kumar VG, Gokavarapu SD, Rajeswari A, Dhas TS, Karthick V, et al. (2011) Facile green synthesis of gold nanoparticles using leaf extract of antidiabetic potent Cassia auriculata. Colloids Surf B Biointerfaces 87: 159-16.

42. Shankar SS, Rai A, Ahmad A, Sastry M (2005) Controlling the optical properties of lemongrass extract synthesized gold nanotriangles and potential application in infrared-absorbing optical coatings. Chem Mater 17: 566-572.

43. Rai A, Singh A, Ahmad A, Sastry M (2006) Role of halide ions and temperature on the morphology of biologically synthesized gold nanotriangles. Langmuir 22: 76-741.

44. Song JY, Kim BS (2009) Rapid biological synthesis of silver nanoparticles using plant leaf extracts. Bioprocess Biosyst Eng 2: 79-84.

45. Shankar SS, Bhargava S, Sastry M (2005) Synthesis of gold nanospheres and nanotriangles by the Turkevich approach. J Nanosci Nanotechnol 5: 17211727.

46. Gardea-Torresdy JL, Parsons JG, Gomez E, Peralta-Videa J, Troiani HE, et al. (2002) Formation and growth of Au nanoparticles inside live alfalfa plants. Nano Lett 2: 97-401.

47. Tréguer-Delapierre M, Majimel J, Mornet S, Duguet E, Ravaine S (2008) Synthesis of non-spherical gold nanoparticles. Gold Bull 41: 195-207.
48. Castro L, Blázquez ML, Muñoz JA, González F, García-Balboa C, et al. (2011) Biosynthesis of gold nanowires using sugar beet pulp. Process Biochem 46 1076-1082.

49. Wang Y, Chen LQ, Li YF, Zhao XJ, Peng L, et al. (2010) A one-pot strategy fo biomimetic synthesis and self-assembly of gold nanoparticles. Nanotechnology 21: 05601.

50. Pei L, Mori K, Adachi M (2004) Formation process of two-dimensional networked gold nanowires by citrate reduction of $\mathrm{AuCl} 4$ - and the shape stabilization. Langmuir 20: 787-784.

51. Sastry M, Ahmad A, Khan MI, Kumar R (2003) Biosynthesis of meta nanoparticles using fungi and actinomycete. Curr Sci 85: 162-170.

52. Dauthal $P$, Mukhopadhyay M (2013) In-vitro free radical scavenging activity of biosynthesized gold and silver nanoparticles using Prunus armeniaca (apricot) fruit extract. J Nanopart Res 15: 1366.

53. Gangula A, Podila R, Ramakrishna M, Karnam L, Janardhana C, et al. (2011) Catalytic reduction of 4-nitrophenol using biogenic gold and silver nanoparticles derived from Breynia rhamnoides. Langmuir 27: 15268-15274.

54. Panigrahi S, Basu S, Praharaj S, Pande S, Jana S, et al. (2007) Synthesis and size-selective catalysis by supported gold nanoparticles: Study on heterogeneous and homogeneous catalytic process. J Phys Chem C 111: 4596-4605.

55. Kalishwaralal K, Deepak V, Ram Kumar Pandian S, Kottaisamy M BarathmaniKanth S, et al. (2010) Biosynthesis of silver and gold nanoparticles using Brevibacterium casei. Colloids Surf B Biointerfaces 77: 257-262.

56. Chandran SP, Chaudhary M, Pasricha R, Ahmad A, Sastry M (2006) Synthesis of gold nanotriangles and silver nanoparticles using Aloe vera plant extract Biotechnol Prog 22: 577-58. 